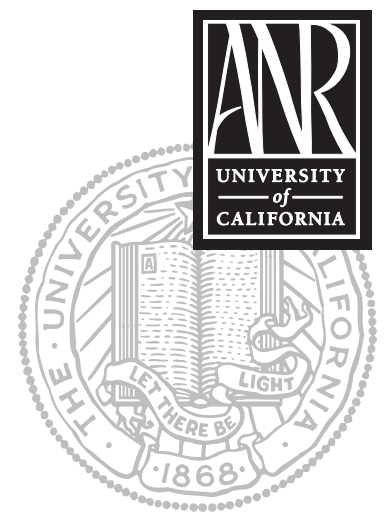

UNIVERSITY OF CALIFORNIA

Division of Agriculture and Natural Resources http://anrcatalog.ucdavis.edu

\title{
Biosecurity for Poultry at Community Farms
}

BRIGID A. MCCREA, Postdoctoral Employee, Department of Animal Science, UC Davis; FRANCINE A. BRADLEY, UCCE Poultry Specialist, UC Davis

Community farms are an excellent way to bring agriculture into the city and allow urban residents to reconnect with mother earth. Many people find that they enjoy raising poultry but do not have the space for a small home flock. A solution to this problem is a community farm. This is a central site where many people raise and maintain poultry or other animals together. These locations are often associated with 4-H and FFA clubs or are alongside community gardens. Community farms need not necessarily be located in a city. Groups that start community farms for poultry must assume responsibility for proper care and disease prevention. The most important step in preserving flock health is the practice of biosecurity.

\section{WHAT IS BIOSECURITY?}

Biosecurity refers to steps taken to prevent introduction of disease into a farm or flock. All bird owners should practice biosecurity, since a good biosecurity plan helps keep disease out of a flock. While all commercial poultry ranches have such plans, it is very simple to modify them for small flocks. Keep in mind that although the following recommendations may sound daunting, you can implement as many components as possible gradually, over weeks, months, or years.

The three main tenets of biosecurity are isolation, traffic control, and sanitation. Traffic control and isolation are effective methods of managing the risk of disease in a flock. If these two components of biosecurity are removed, is a poultry venture doomed to fail? Hopefully not, but added vigilance will be needed with regard to sanitation, the final tenet of biosecurity.

Sanitation includes the cleaning and disinfection (C\&D) of all equipment and materials that enter or remain on the farm. It also includes proper personal hygiene for people at the farm. Both are crucial in order to eliminate the presence of disease agents. Small flock owners have control over many factors that contribute to the spread of disease, such as disposing of dead birds; the arrival of carrier birds; dealing with sick birds; contact with contaminated objects (fomites) such as clothing, footwear, feed, feed sacks, soil, and old bedding; and contact with rodents, insects, and wild birds (for more information, see PFS 26, Biosecurity for Poultry Flocks, http://animalscience .ucdavis.edu/Avian/pfs26.htm). Sanitation is intended to eliminate disease agents before they can be spread to or within a farm.

\section{CARETAKER RESPONSIBILITIES}

In 4-H and FFA poultry projects on community farms, many families often care for their birds on a daily basis. A 4-H or FFA leader or instructor may develop a regular schedule in which families take turns caring for the community flock as a whole. Even if a community flock may have many caretakers, it is considered as one biosecurity unit. Caretakers must avoid contact with other poultry or birds (parrots, birdfeeder stations, chickens, caged birds, etc.) before caring for the community flock. These other birds can be asymptomatic, that is, they may look healthy but be carriers of poultry disease agents. Caretakers or visitors must not enter if they have been in contact with other birds during the last 24 hours. If such contact has taken place, they must take a complete shower and change clothing before caring for the community 
flock. Overshoes (rubber or plastic boots) should be worn on the premises during daily flock care visits. These overshoes should be worn through a footbath (see ANR Publication 8201, Biosecurity Footbaths: Easier Than You Think!) before and after care of the birds. These simple steps aid in preserving isolation and reduce traffic around the flock as individuals who are less interested in complying with biosecurity protocols will be deterred from entering.

County, regional, or small-animal program leaders can recommended biosecurity solutions and ideas to individual clubs or schools. Anything that affects one flock can affect other flocks in the surrounding area. Leaders should work with their members to implement the following four pillars of flock health preparedness:

1. Procedure development

2. Junior and teen leader projects

3. Planned flock testing

4. Quarantine area

A clean and healthy environment for animals at a community farm has many ramifications for the neighborhood as a whole. Neighbors appreciate a farm with clean pens, no strong odors, and a tidy appearance. It may be prudent to plant a visual barrier such as trees and shrubs to keep casual onlookers from entering without permission. Although it may seem harmless for such individuals to enter, microorganisms can reside in hair, clothing, and nasal passages for days or weeks. These individuals would then become unwitting participants in the introduction and spread of poultry disease.

Weeds and excess vegetation are areas where rodents can hide and should be removed once a month; also eliminate junk piles that can harbor rodents. If needed, implement rodent, wild bird, and insect control measures (see PFS 23: Rodenticides for Control of Norway Rats, Roof Rats and House Mice, http://animalscience.ucdavis.edu/ Avian/pfs23.htm). Neighbors who suspect that a community farm is a source of pests may launch complaints. Mosquitoes are vectors of fowl pox; remove sources of standing water that can serve as breeding sites. Do not let birds run loose on the farm, as they may enter unsafe areas or neighboring yards. Take the time to put solid covers on pens and make repairs to keep wild birds away from poultry feed and water. A well-maintained community farm has a nice appearance and can enhance neighborhood property values. Community farms, if managed appropriately, can be valuable resources for members of the neighborhood and greater municipality.

\section{Procedure Development}

A procedure can be a guideline, set of rules, code of behavior, or protocol. Community farm leaders and instructors should make procedure development a priority. A procedure is a clear communication, using written or photographic explanations, of how to perform a specific task. Excellent planning in areas of $C \& D$, notification, emergency action, the advdition of new or show birds, and travel to or from feed stores will benefit the community flock. Community farm leaders should work with their UCCE poultry extension specialist to customize the procedures for individual community farms.

- All procedures should be accompanied by an explanation or demonstration to answer questions by new and returning members. Flock maintenance is often done on a rotating basis among project members who share the space, so training must take place.

- Records indicating who was responsible for certain duties can be very helpful in assessing disease control efforts for the community flock.

- Procedures should be posted and kept on-site in a binder. Sheet protectors or lamination help ensure that the materials stay clean. Binders should be kept in a secure cabinet or feed room. Master copies of procedures should be kept by the project leader. 


\section{Cleaning and disinfection}

Procedures should be developed for daily, weekly, and monthly C\&D activities. Developing procedures for the items listed below is made easier with the selection of a suitable disinfectant. Store the C\&D agents with directions on how to mix fresh batches. Always follow the directions on the label and always remove all organic material before applying a disinfectant. See the UCCE publication PFS 27: Sanitation-Disinfection Basics (http://animalscience.ucdavis.edu/Avian/pfs27.htm) for more information on C\&D.

- Daily duties include changing feed and water, collecting eggs, and spot-cleaning wet areas of litter.

»Empty and scrub water containers daily, since disease agents survive well in water. After scrubbing with a brush, spray containers with a disinfectant and allow them to sit for the prescribed time before rinsing and refilling. Placing water containers on raised wire allows birds to be separated from the wet litter beneath; this is especially prudent with waterfowl.

» Provide fresh feed daily; old feed can harbor disease-causing mold. If the feed containers have been washed (part of monthly C\&D), dry them thoroughly before adding feed to prevent mold growth.

» Egg collection flats are easily cleaned and disinfected; however, only those made of plastic can be cleaned. Transporting dirty flats between locations (e.g., between home and the farm) can contaminate multiple sites (farm, car, kitchen counter, etc.). Plastic egg flats or egg filler flats are available online (see the Resources at the end of this publication) for approximately $\$ 3.00$ each.

-Weekly duties include C\&D of commonly used equipment (i.e., shovels, scoops, rakes, hoses), litter removal and replacement, perch cleaning, nest cleaning, and footbath cleaning.

» Perform C\&D of equipment at the end of the regular daily or weekly cleaning routine. Wash and scrub surfaces to remove organic material before applying disinfectants. Store equipment in a secure location when not in use.

» Replace old litter with fresh bedding material to ensure that birds are separated from organisms passed along in the fecal material. Remove old litter to a compost pile or covered waste receptacle. If neither is available, double-bag the litter in a location that is remote from the coop. It is better to spread the litter rather than pile it, as long as it is located away from other poultry. Litter that is spread will dry quickly, have fewer odors, and sunlight will aid in the rapid destruction of harmful microorganisms. Squatting at the bird's eye level and taking a breath will quickly indicate whether there is a strong ammonia odor. If the smell is strong or your eyes water or burn, clean the pen.

» Scrape fecal material from perches. Examine perches for physical hazards and make repairs. Disinfect perches.

»Clean and replace nests and nesting materials. Clean the inside of nests before disinfection. Scrub plastic nest pads to remove all organic material, then soak the pads in disinfectant. Add fresh nest material, if used, to a clean and dry nest to prevent mold growth.

»Depending on the season, clean and replenish footbaths when they begin to look soiled (this indicates the presence of organic material). Footbath containers must be emptied, scrubbed, and refilled with disinfectant. It should be the responsibility of all who use the poultry facility to clean and replenish the footbath if it is dirty (see ANR Publication 8021, Biosecurity Footbaths: Easier Than You Think!). 
- Monthly duties include cobweb removal, dust removal, and C\&D of feed containers. » Remove cobwebs with a broom; remove dust with high-pressure water or a whisk broom. Cobwebs and dust that accumulate in corners can harbor microorganisms for long periods of time.

" If possible, clean the containers in which feed is kept. The timing of this should correspond with the arrival of each new feed delivery. A good idea is to keep feed in one of two plastic or metal garbage cans with tight-fitting lids. Keep one feed container cleaned and ready to receive a new feed delivery.

- Schedule twice-a-year C\&D that includes a thorough cleaning of the entire coop followed by the C\&D of all surfaces. This should also be performed upon the detection of a sick bird or parasites of any kind.

- Clean transport containers immediately after use. Clean and disinfect containers before they are stored in or near bird areas to prevent the movement of microorganisms onto the farm. Store containers in a secure area.

- When mixing large quantities of a cleaning agent or disinfectant, prepare only as much as will be used immediately so that disposal of excess material will not be necessary.

- Provide contact information for the community farm leader in case of questions.

\section{Emergency action}

Procedures should be developed for emergency action if a bird in the flock falls ill, is injured, or is found dead. Sick or injured birds should immediately be placed in a quarantine area (see the section "Quarantine Area," below).

- Contact information for the owners of all birds should be printed clearly and posted in a common location. Owners should provide alternate telephone numbers, such as cell phones, for at least two family members. The community farm leader or instructor should be informed immediately if there is a change in any telephone number.

- Brainstorm with other bird owners to develop an emergency action plan. If veterinary care is required, follow the procedure that has been agreed upon by all bird owners. Everyone who uses the poultry facility should sign an agreement to abide by the procedure for emergency veterinary care. The agreed-upon procedure should be followed if the owners cannot be contacted at any of the telephone numbers they have provided.

- Farms often keep a first aid kit on hand for humans; another first aid kit for the flock is a good idea. The poultry first aid kit should be kept in a feed room or other secure location. Suggested items for a poultry first aid kit include a styptic pencil or similar product, gauze and tape, scissors, iodine soap (betadine), and paper towels. Keep a checklist of the contents in the kit for ease in replacing used items.

- Inform members of procedures regarding dead birds destined for necropsy and practice good personal hygiene. Make plastic bags available for handling carcasses (carcasses should be triple-bagged). Local veterinarians may perform a necropsy for a fee; however, the California Animal Health and Food Safety Laboratory System (CAHFS) has a policy of performing free necropsies for backyard flocks. A necropsy may also be performed on a sick or dying bird. Keep a telephone number and map on hand for the nearest CAHFS lab. For more information on CAHFS, see the Resources.

- Disinfect leg bands from dead birds before using them on other birds.

- Move birds that have parasites to the quarantine area. Keep poultry dust on hand in the quarantine area for birds found carrying mites or lice. Plan to clean the main coop as a whole before the external parasites spread to other birds. For details on developing your quarantine area, see the section "Quarantine Area," below. See ANR Publication 8162, Common Lice and Mites of Poultry: Treatment and Identification (http://anrcatalog. ucdavis.edu/pdf/8162.pdf) for additional information on treating external parasites. 
Make plans to educate those who share the space about the cause of a poultry illness or death. Allow other owners to make changes or decisions for their birds based on sound test results. Do not assume that an ill bird has not transmitted a disease to other flock members.

\section{Adding new or show birds}

Procedures should be developed for adding new birds or returning show birds to the flock. Maintain the quarantine area in good condition, since impulse purchases may be made at poultry shows or other locations. Birds returning from fairs or shows, as well as new birds, can be swabbed, blood-tested, vaccinated, and wormed while in quarantine. A minimum of 2 to 3 weeks of isolation is recommended in order to consider the longest incubation periods for federally reportable poultry diseases.

Travel to and from feed stores

Owners from several farms often gather in feed stores. Community farm leaders should recommend good biosecurity practices for those who visit feed stores. This includes protocols for wearing specified shoes or disposable plastic boots at the feed store, cleaning the floorboards of the car upon return, and unloading feed into clean feed containers.

- At a feed store (or other location where poultry owners gather), be sure to wear shoes specified as for use only at the feed store. These shoes can be kept in a plastic bag in the car and worn only while in the feed store. An economical alternative is to wear disposable plastic boots (see the Resources).

- Vacuum the floorboards and carpets of the car upon return from the feed store. Alternatively, use removable rubber or plastic floor mats and perform $C \& D$ on them following each visit.

- Cars can carry microorganisms on tires and in wheel wells. Upon return from the feed store, park a safe distance from the poultry coop. If this is not convenient for carrying heavy feed sacks, place a clean feed container on a dolly or cart and move it to the vehicle parking area. Place the feed directly into the clean container and immediately discard the bags. Be sure to tape the feed tag to the lid of the feed container.

\section{Junior and Teen Leader Projects}

Every poultry project has at least one exceptional member who has knowledge and poultry skills beyond simple showmanship and poultry washing. These members are ready for the additional responsibility of training new members about biosecurity protocols. These members can also perform monthly supply checks of logbooks, pens, trash bags, disinfectant levels, and so on. Junior and teen leaders can also perform demonstrations on the following topics.

- Cleaning and disinfection: the correct methods of C\&D; what to use and where it is to be used.

- External parasites: how to clean a poultry house of parasites.

- Record keeping: how to implement and maintain a biosecurity checklist.

- Footbaths: how to set up and maintain a footbath.

\section{Side projects}

Junior and teen leaders should be encouraged to take on small side projects with the community flock. These projects can range from a simple improvement of a coop to an advanced set of instructions for the development, maintenance, and verification of regular biosecurity procedures and records. The demonstration topics listed above are good side projects for more-sophisticated members. 


\section{Planned Flock Testing}

Periodically test flocks for parasites, viruses, or bacteria. Parasites often deposit their eggs in bird feces. Almost any veterinarian can examine a fresh stool sample (collected in a Ziploc bag) by using a fecal flotation test. This test can detect worm as well as coccidia eggs. An owner may choose to have a veterinarian or other skilled individual perform a blood draw on birds in the flock. At least 1 cubic centimeter (cc) of blood per bird should be collected, kept cool, handled gently, and transported immediately for analysis. The cost of a blood screen at CAHFS is typically affordable, but call for an estimate at the nearest lab (see the Resources). Costs may vary at local veterinary clinics. Also, contact the nearest CAHFS laboratory to ask for the name of the preferred blood collection tubes. Use this opportunity to teach project members about careers in veterinary medicine or have an avian veterinarian as a guest speaker during a meeting.

\section{Quarantine Area}

Birds that are purchased should be quarantined for a minimum of 2 to 3 weeks before being introduced into the flock. Any bird that develops disease symptoms during this period should remain quarantined until it has been diagnosed and treated and found to be disease-free. When planning a day's work, always care for the birds in quarantine last. Equipment in the quarantine area should never leave the area. Mark equipment dedicated to the quarantine area with red tape. Clean the quarantine area last in the daily routine; do not return to the regular coop for any reason after entering the quarantine area. Post signs to designate the quarantine area. Additionally, post signs at the main entrance of the community farm to indicate that it is a biosecure area and disease control measures are in place (see the resources at the end of this publication).

If possible, place coveralls of various sizes in a dedicated covered plastic tub or garbage can near the quarantine area. Wear these coveralls while cleaning and caring for quarantined birds and return them immediately to the tub or can when finished. Launder the coveralls once a week. Alternatively, members may wish to keep coveralls and boots in a locker or garbage can at the entrance of the community farm. Community members should use this safety measure to prevent carrying contaminants home on clothing and footwear.

\section{CONCLUSION}

Insist on cooperation among those who wish to raise birds at the community farm. On a small farm, the equipment needed to maintain biosecurity may be simple and relatively inexpensive. In all cases, cleaning and disinfection requires planning, the will to do an effective job, and some investment of time, money, and effort. Here are some additional suggestions.

- Keep a waterless hand sanitizer in vehicles for use when returning from the feed store, veterinarian's office, or community farm. Be sure to work the sanitizer between fingers and under fingernails.

- Consistently remind those who use the space to follow biosecurity procedures. Spot checks for compliance by qualified leaders may occasionally be performed.

- Although isolation may seem impossible, it can be as easy as a fence and gate.

- Keep locks on all disinfectants cabinets and label them with a poison sign if required.

- A posted biosecurity sign is the first line of defense against disease. Let others know when it is not safe to enter, for example, as when a disease is suspected.

Review publications on biosecurity to find ways to reduce the risk to the community flock. Although this publication was designed with 4-H and FFA community farms in mind, the recommendations in it can be customized to the needs of any farm. Many of 
these recommendations will take time to implement. To assist in this process, put together short-term and long-term calendars for implementing your biosecurity goals. Above all, do not give up on biosecurity improvements. Seek advice from others, such as UCCE county farm advisors or poultry extension specialists. In an effort to minimize foot traffic around the flock at a community farm, owners should examine their biosecurity procedures and share innovative solutions to biosecurity dilemmas with others. The entire poultry community can benefit from improved health and a lowered risk of disease. After all, poultry depend upon their owners for healthy living in a clean and safe environment.

\section{RESOURCES}

\section{Publications}

McCrea, B., J. Jeffrey, R. Ernst, and A. Gerry. 2005. Common lice and mites of poultry: Treatment and identification. Oakland: University of California Agriculture and Natural Resources Publication 8162. ANR CS Web site, http:// anrcatalog.ucdavis.edu/pdf/8162.pdf.

Poultry Fact Sheet (PFS) No. 23: Rodenticides for control of Norway rats, roof rats, and house mice. UC Poultry Web Page, http://animalscience.ucdavis.edu/ Avian/pfs23.htm.

Poultry Fact Sheet (PFS) No. 26: Biosecurity for poultry flocks. UC Poultry Web Page, http://animalscience.ucdavis.edu/Avian/pfs26.htm.

Poultry Fact Sheet (PFS) No. 27: Sanitation-disinfection basics. UC Poultry Web Page, http://animalscience.ucdavis.edu/Avian/pfs27.htm.

\section{California Animal Health and Food Safety Laboratory System (CAHFS)}

CAHFS will perform a free diagnosis of sick or dead backyard poultry at multiple locations in the state of California. CAHFS also performs free necropsies. CAHFS labs are not treatment facilities; all birds taken to the lab will remain at the lab. The main CAHFS lab at UC Davis also has swab kits for avian influenza and exotic Newcastle disease testing. For more information, see the CAHFS Web site, http://cahfs.ucdavis.edu/.

\section{Biosecurity Signs}

Gempler's, http://www.gemplers.com/safety/labels/biosecsign.

Penn State University Biosecurity and On-Farm Food Safety Web site, http://vetextension.psu.edu/biosecurity/.

\section{Disposable Plastic Boots}

eNasco, http://www.enasco.com/; search for the Nasco Big Boot.

QC Supply, http://www.qcsupply.com/; search for disposable boots.

Safety Central, http://www.safetycentral.com/; search for Knot-A-Boot.

\section{Egg Filler Flats or Egg Trays}

Eggboxed, http://www.eggboxes.com/cat--Egg-Filler-Flats--Egg+Trays.html.

Egg Cartons, http://www.eggcartons.com/catalog.htm. 


\section{FOR FURTHER INFORMATION}

To order or obtain ANR publications and other products, visit the ANR Communication Services online catalog at http://anrcatalog.ucdavis.edu or phone 1-800-994-8849. You can also place orders by mail or FAX, or request a printed catalog of our products from University of California Agriculture and Natural Resources Communication Services 6701 San Pablo Avenue, 2nd Floor Oakland, California 94608-1239

Telephone 1-800-994-8849

(510) 642-2431

FAX (510) 643-5470

E-mail: danrcs@ucdavis.edu

This publication has been anonymously peer reviewed for technical accuracy by University of California scientists and other qualified professionals. This review process was managed by the ANR Associate Editor for Animal, Avian, and Aquaculture Sciences.

Publication 8280

ISBN-13: 978-1-60107-524-6

(C)2008 The Regents of the University of California

Division of Agriculture and Natural Resources

All rights reserved.

No part of this publication may be reproduced, stored in a retrieval system, or transmitted, in any form or by any means, electronic, mechanical, photocopying, recording, or otherwise, without the written permission of the publisher and the authors.

The University of California prohibits discrimination or harassment of any person on the basis of race, color, national origin, religion, sex, gender identity, pregnancy (including childbirth, and medical conditions related to pregnancy or childbirth), physical or mental disability, medical condition (cancer-related or genetic characteristics), ancestry, marital status, age, sexual orientation, citizenship, or status as a covered veteran (covered veterans are special disabled veterans, recently separated veterans, Vietnam era veterans, or any other veterans who served on active duty during a war or in a campaign or expedition for which a campaign badge has been authorized) in any of its programs or activities. University policy is intended to be consistent with the provisions of applicable State and Federal laws.

Inquiries regarding the University's nondiscrimination policies may be directed to the Affirmative Action/Staff Personnel Services Director, University of California, Agriculture and Natural Resources, 1111 Franklin Street, $6^{\text {th }}$ Floor, Oakland, CA 94607-5201, (510) 987-0096. For information about ordering this publication, telephone 1-800-994-8849.

To simplify information, trade names of products have been used. No endorsement of named or illustrated products is intended, nor is criticism implied of similar products that are not mentioned or illustrated. 